\title{
Low maternal serum pregnancy-associated plasma protein-A as a risk factor of preeclampsia
}

\author{
Suchaya Luewan ${ }^{1}, M D$, Monrudee $\underline{\text { Teja-intr }^{1}}$, MD, Supatra Sirichotiyakul ${ }^{1}$, MD, Theera Tongsong $^{1}$, MD
}

\begin{abstract}
INTRODUCTION Low levels of pregnancy-associated plasma protein-A (PAPP-A) might be associated with abnormal placentation, leading to the development of preeclampsia during late gestation. We aimed to determine the association between low serum PAPP-A levels and rates of preeclampsia in Thai women with otherwise low-risk pregnancies.

METHODS A cohort study was conducted on consecutive singleton pregnancies undergoing first trimester screening for fetal Down syndrome at a tertiary centre hospital. A prospective database was assessed for patient records, including PAPP-A levels, pregnancy outcomes and obstetrics complications. Pregnancies with potential causes of preeclampsia were excluded. Enrolled women were categorised into two groups: women with normal PAPP-A levels ( $\geq 10$ th percentile; control group); and those with low PAPP-A levels (<10th percentile; study group). The main outcome measure was rate of preeclampsia.

RESULTS Of 6,887 women screened, 3,830 were available for analysis and 167 were excluded due to potential confounders. Of the remaining 3,663 women enrolled, 357 women were categorised as having low PAPP-A levels and 3,306 had normal PAPP-A levels. The prevalence of preeclampsia ( $8.4 \%$ vs. $2.6 \%)$ and early-onset preeclampsia (i.e. before 34 weeks of gestation) ( $1.1 \%$ vs. $0.1 \%$ ) was significantly higher (relative risk 3.27 and 9.26 , respectively) in women from the study group than in the control group.

CONCLUSION Pregnancy with PAPP-A levels < 10th percentile was significantly associated with an increased risk of preeclampsia that tended toward early development. Therefore, pregnant women with low PAPP-A levels in the first trimester should be considered to be at increased risk of preeclampsia.
\end{abstract}

Keywords: first trimester Down syndrome screening, PAPP-A, preeclampsia

\section{INTRODUCTION}

Preeclampsia remains a major cause of both maternal-fetal morbidity and mortality, with reported incidences in the range of $2 \%-18 \%{ }^{(1-4)}$ Early identification of women at high risk of developing such disorders could help physicians to provide appropriate care. The traditional method of screening for preeclampsia is careful taking of maternal history, such as number of children, high body mass index, and previous or family history of preeclampsia. However, studies have found that screening on this basis alone could identify only $30 \%$ of women who developed hypertensive disorders in pregnancy. ${ }^{(5)}$ At present, there is no single screening test that is considered reliable and cost-effective for predicting preeclampsia. ${ }^{(3)}$

Pregnancy-associated plasma protein-A (PAPP-A) is a biochemical marker used for fetal Down syndrome screening. PAPP-A is a high-molecular-weight glycoprotein produced in the placenta and secreted into the maternal bloodstream. It is believed that placental pathology can lower PAPP-A levels. ${ }^{(6-9)}$ The aetiology of preeclampsia is unknown, but some potential aetiologies include abnormal trophoblast invasion of uterine blood vessels, and immunological intolerance between fetoplacental and maternal tissues. ${ }^{(3)}$ For this reason, low PAPP-A levels may be associated with development of subsequent preeclampsia. The association of low first trimester levels of PAPP-A with adverse pregnancy outcomes, including preeclampsia, has been demonstrated in multiple studies, ${ }^{(10-16)}$ although the cut-off levels of PAPP-A varied in each study. According to a large population-based study (FASTER trial), pregnancies with PAPP-A levels $<10$ th percentile $(0.52$ multiples of the normal median $[\mathrm{MoM}]$ ) were significantly associated with preeclampsia, low birth weight, preterm birth, preterm rupture of membrane and neonatal death. ${ }^{(10-16)}$

The objective of the present study was to determine the association between unexplained low serum PAPP-A levels and rates of preeclampsia among low-risk pregnancies in Thailand. Thai-specific reference ranges were used, as several studies have demonstrated that ethnicity influences the levels of biochemical markers, ${ }^{(17-19)}$ suggesting that all ethnic groups should have their own reference ranges for biomarkers. Normal reference ranges for serum PAPP-A levels in the Thai population also differ from those in a Caucasian population. ${ }^{(20)}$

\section{METHODS}

Using a prospective database from a fetal Down syndrome screening programme, a retrospective cohort study was undertaken on consecutive pregnancies that underwent first trimester screening for fetal Down syndrome in the northern part of Thailand, including 32 network hospitals. The database has been in existence since 2010, when it was developed as part of a project on prenatal diagnosis and control of Down syndrome for the National Research University under the Office of the Higher Education Commission, Thailand. 
As part of the database's development, all singleton pregnant women in the first trimester who attended antenatal care clinics at network hospitals were offered serum marker screening for fetal Down syndrome regardless of maternal age. Baseline demographic data such as maternal age, parity, body weight, ethnic origin, smoking habits or illicit drug use, and underlying medical or familial disease, was assessed and prospectively recorded in the database at the time of blood sample collection.

Collected blood samples were immediately transferred to the laboratory for centrifugation and serum separation. The bioassays for PAPP-A and free beta-human chorionic gonadotropin ( $\beta$-hCG) were performed in batches to eliminate interassay variations using the DELFIA $®$ Xpress system (PerkinElmer, Waltham, MA, USA). Absolute concentrations of serum PAPP-A and free $\beta$-hCG were calculated for MoM using Thai gestation-specific medians and weight corrections as reference range values. ${ }^{(20)}$

Ethics approval was received from the institutional review board. The database was assessed for all records made between 2010 and 2012. Only patients whose records had complete information, including gestational age at sample collection and delivery, medical and obstetric complications, pregnancy outcomes, and concentrations of serum markers, were recruited Inclusion criteria were as follows: (a) singleton pregnancy; (b) Thai ethnicity; (c) accurate gestational age that relied on crownrump length (sonographically measured in the first trimester) and certain last menstrual period; (d) no history of preeclampsia in previous pregnancies; and (e) no underlying medical or obstetric complications, such as chronic hypertension, maternal diabetes mellitus, renal disease and maternal obesity (defined as body weight $>80 \mathrm{~kg}$ ). Pregnant women with fetal anomalies and fetal chromosomal abnormalities were excluded from the study.

Recruited women were categorised into two groups: control group with normal PAPP-A levels ( $\geq 10$ th percentile; equivalent to $0.53 \mathrm{MoM})$; and study group with low PAPP-A levels $(<10$ th percentile). The main outcome was the rate of preeclampsia in the two groups. Preeclampsia was defined as new onset of hypertension (> 140/90 $\mathrm{mmHg}$ ) and either proteinuria (24-hour urine protein > $300 \mathrm{mg}$ ) or end-organ dysfunction after 20 weeks of gestation in a previously normotensive woman. Severe hypertension and signs or symptoms of end-organ injury were considered to indicate severe disease. ${ }^{(1,21)}$ Eclampsia referred to the development of grand mal convulsions in a woman with preeclampsia in the absence of other neurologic conditions that could account for the convulsions. Participants were categorised into two groups based on their onset of preeclampsia, taking into account the total prevalence of preeclampsia and the prevalence of early-onset preeclampsia (i.e. before 34 complete weeks of gestation).

Statistical analysis was performed using IBM SPSS Statistics for Windows version 21.0 (IBM Corp, Armonk, NY, USA). Comparisons of baseline characteristics between the two groups were performed using Student's $t$-test for continuous variables with normal distribution, while chi-square or Fisher's exact tests were used for categorical variables. A p-value $<0.05$ was considered to be statistically significant. Relative risks and 95\%

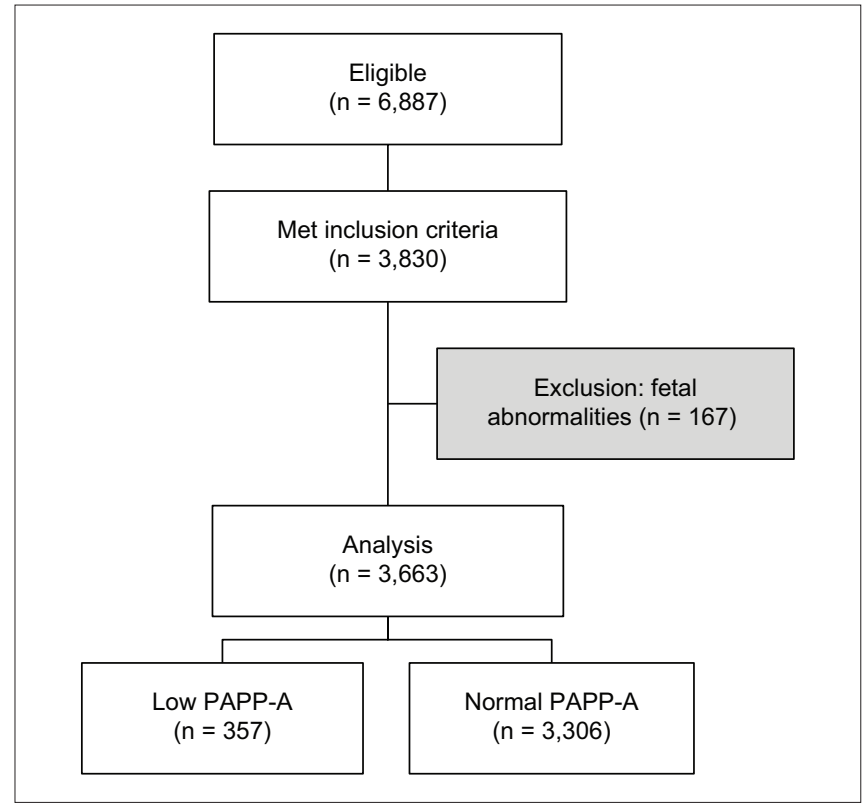

Fig. 1 Flowchart shows enrolment of pregnant women in the present study. PAPP-A: pregnancy-associated plasma protein-A

Table I. Baseline characteristics of women with low or normal PAPP-A levels.

\begin{tabular}{lccc}
\hline Characteristic & \multicolumn{2}{c}{ Mean \pm SD/No. (\%) } & \multirow{2}{*}{ p-value } \\
\cline { 2 - 3 } & $\begin{array}{c}<\text { 10th } \\
\text { percentile } \\
(\mathbf{n}=\mathbf{3 5 7})\end{array}$ & $\begin{array}{c}\mathbf{2} \text { 10th } \\
\text { percentile } \\
(\mathbf{n}=\mathbf{3 , 3 0 6 )}\end{array}$ & \\
\hline Maternal age (yr) & $31.2 \pm 4.7$ & $30.9 \pm 4.7$ & $0.204^{*}$ \\
Maternal weight (kg) & $58.0 \pm 9.6$ & $53.5 \pm 8.0$ & $<0.001^{*}$ \\
Gestational age (day) & $85.9 \pm 5.2$ & $86.6 \pm 6.1$ & $0.019^{*}$ \\
on blood sampling day & & & \\
Nulliparity & $203(56.9)$ & $1,954(59.1)$ & $0.428^{+}$ \\
\hline
\end{tabular}

*Student's $t$-test. +Chi-square test. PAPP-A: pregnancy-associated plasma protein-A; SD: standard deviation

confidence intervals (Cls) for preeclampsia were calculated for pregnancies with low PAPP-A levels. In order to obtain a power of $80 \%$ at $95 \% \mathrm{Cl}$ for a relative risk of 3 , for an estimated incidence of preeclampsia of $2.5 \%$ in low-risk women with normal PAPP-A levels, the study needed a sample size of at least 295 women with low serum PAPP-A levels.

\section{RESULTS}

During the study period, a total of 6,887 pregnancies were screened (Fig. 1). However, 3,057 pregnant women were not included due to incomplete or unavailable medical records for pregnancy outcomes, mostly due to women giving birth in remote rural areas and difficulties with follow-up. Only 3,830 pregnant women met the inclusion criteria and had complete data. Of these, 167 women were excluded because of fetal anomalies $(\mathrm{n}=114)$ and fetal chromosome abnormalities $(\mathrm{n}=53)$. The remaining 3,663 women were available for analysis. Among these, 357 women were categorised in the group with low PAPP-A levels (study group) and 3,306 women had normal PAPP-A levels (control group). Table I presents the baseline characteristics of patients in the two groups. 
Table II. Incidence of preeclampsia among women with low or normal PAPP-A levels.

\begin{tabular}{|c|c|c|c|c|c|}
\hline \multirow[t]{2}{*}{ Variable } & \multicolumn{3}{|c|}{ No. (\%) } & \multirow[t]{2}{*}{ p-value } & \multirow[t]{2}{*}{ Relative risk $(95 \% \mathrm{Cl})$} \\
\hline & $\begin{array}{c}<\text { 10th percentile } \\
(n=357)\end{array}$ & $\begin{array}{l}\geq 10 \text { th percentile } \\
(n=3,306)\end{array}$ & $\begin{array}{c}\text { Total } \\
(n=3,663)\end{array}$ & & \\
\hline Early-onset preeclampsia & $4(1.1)$ & $4(0.1)$ & $8(0.2)$ & $0.0016^{+}$ & $9.26(2.33-36.87)$ \\
\hline
\end{tabular}

${ }^{*}$ Chi-square test. + Fisher's exact test. $\mathrm{Cl}$ : confidence interval; PAPP-A: pregnancy-associated plasma protein-A

Table III. Diagnostic indices for predicting preeclampsia.

\begin{tabular}{lcc}
\hline Variable & No. (\%) & OR (95\% CI) \\
\hline Sensitivity & $30 / 115(26.1)$ & $26.1(18.1-34.1)$ \\
Specificity & $3,221 / 3,548(90.8)$ & $90.8(89.8-91.7)$ \\
Positive predictive & $30 / 357(8.4)$ & $8.4(5.5-14.7)$ \\
value & & \\
Negative predictive & $3,221 / 3,306(97.4)$ & $97.4(95.8-99.1)$ \\
value & & \\
\hline
\end{tabular}

Cl: confidence interval; OR: odds ratio

Table IV. Incidence of other obstetric outcomes among women with low or normal PAPP-A levels.

\begin{tabular}{|c|c|c|c|}
\hline \multirow[t]{2}{*}{ Characteristic } & \multicolumn{2}{|c|}{ Mean \pm SD/No. (\%) } & \multirow[t]{2}{*}{ p-value } \\
\hline & $\begin{array}{c}<10 \text { th } \\
\text { percentile } \\
(n=357)\end{array}$ & $\begin{array}{c}\geq 10 \text { th } \\
\text { percentile } \\
(n=3,306)\end{array}$ & \\
\hline $\begin{array}{l}\text { Gestational age at } \\
\text { delivery (wk) }\end{array}$ & $36.7 \pm 5.9$ & $38.1 \pm 2.7$ & $<0.001^{*}$ \\
\hline Birth weight (g) & $2,746 \pm 945$ & $3,035 \pm 526$ & $<0.001^{*}$ \\
\hline Stillbirth & $34(9.5)$ & $44(1.3)$ & $<0.0001^{+}$ \\
\hline \multicolumn{4}{|l|}{ Low Apgar score $(<7)$} \\
\hline At $1 \mathrm{~min}$ & $51(14.3)$ & $209(6.3)$ & $<0.0001^{+}$ \\
\hline At $5 \mathrm{~min}$ & $36(10.1)$ & $70(2.1)$ & $<0.0001^{+}$ \\
\hline Preterm birth (< 37 wk) & $58(16.2)$ & $263(8.0)$ & $<0.0001^{\dagger}$ \\
\hline Fetal growth restriction & 39 (10.9) & $216(6.5)$ & $0.0020^{+}$ \\
\hline
\end{tabular}

*Student's $t$-test. +Chi-square test. PAPP-A: pregnancy-associated plasma protein-A; SD: standard deviation

When the study group was compared with the control group, the rates of preeclampsia $(8.4 \%$ vs. $2.6 \%)$ and earlyonset preeclampsia $(1.1 \%$ vs. $0.1 \%)$ were significantly higher in women with low PAPP-A levels, with a relative risk of 3.27 and 9.26, respectively (Table II). Low PAPP-A levels, at cut-off $<10$ th percentile, could predict preeclampsia with a sensitivity of $26.1 \%$ and false positive of $9.2 \%$ (specificity $90.8 \%$ ), with an area under the receiver operating characteristic curve of 0.613 (Table III \& Fig. 2). Other adverse obstetric outcomes, such as gestational age at delivery, birth weight, stillbirth, Apgar scores at one minute and five minutes, preterm birth, and fetal growth restriction, were significantly higher among women with low PAPP-A levels (Table IV).

\section{DISCUSSION}

The main objective of this study was to determine the association between low serum PAPP-A levels and the rate of preeclampsia. We found that pregnancies with low PAPP-A levels were significantly associated with an increased risk of preeclampsia, especially early-onset preeclampsia. Although we did not perform

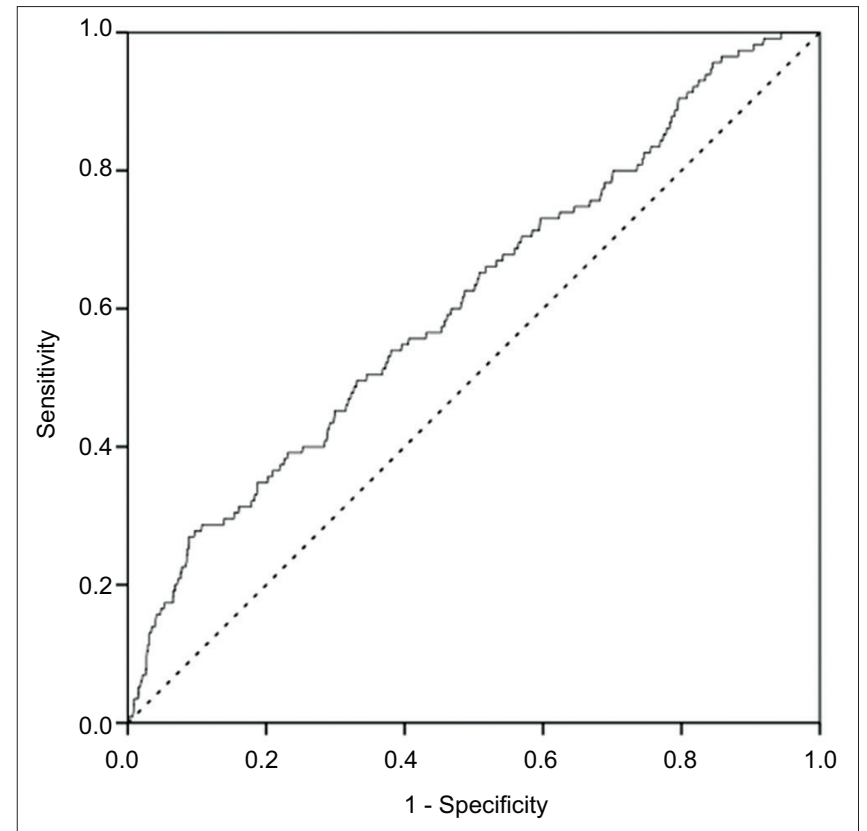

Fig. 2 Receiver operating characteristic curve for predicting preeclampsia using pregnancy-associated plasma protein-A levels shows area under the curve of 0.613 .

multivariate analysis, women with known potential risk factors for preeclampsia were excluded from the study prior to enrolment. This was done in order to determine whether unexplained low PAPP-A levels would be an independent risk factor among pregnancies that were otherwise deemed to be at low risk of preeclampsia. Parity, which might be involved in the prevalence of preeclampsia, was not controlled in our study. However, the distribution of parity was not significantly different between the two patient groups. Therefore, nulliparity was unlikely to have confounded the primary outcomes of our study.

As maternal obesity may increase the risk of preeclampsia, obese women (body weight $>80 \mathrm{~kg}$ ) were excluded from the analysis. It should be noted that maternal weight was still significantly higher in pregnancies with low PAPP-A levels in our study, which was consistent with previous studies. ${ }^{(17,20,22)}$ This was likely caused by the dilutional effect of higher blood volume among larger mothers. Therefore, while higher maternal weight might have possibly confounded the outcomes in our study, any such effect was likely to have been minimal, as women with obesity were not included in the analysis. Gestational age at the time of blood sampling was also significantly different between the two groups. However, it was a difference of only one day, and thus was probably due to coincidence and unlikely to have had any clinical effect on the development of preeclampsia. 
Currently, first trimester screening with serum markers is commonly used for fetal Down syndrome screening in the Thai population. Therefore, data on PAPP-A levels is available for a great number of pregnant women in our region. Although the primary purpose of assessment of first trimester serum markers is fetal Down syndrome screening, these markers are informative and may be useful in predicting preeclampsia as well as other adverse obstetric outcomes. To date, several biomarkers and new technologies have been evaluated as screening tests for predicting preeclampsia in late gestation and were found to be useful, (23-26) such as soluble fms-like tyrosine kinase-1, placental growth factor, vascular endothelial growth factor and uterine artery Doppler scans at mid-pregnancy, but none of these screening tests have proven to be cost-effective and are not recommended for routine practice. ${ }^{(21)}$ On the other hand, PAPP-A is a biomarker that is part of routine screening for Down syndrome in the first trimester and can have the added benefit of predicting the likelihood of preeclampsia without any extra effort. This information may be clinically useful, especially in areas where preeclampsia is an important health problem, such as Thailand.

Early detection of preeclampsia is essential for successful pregnancy outcomes in women at risk of developing preeclampsia, as it would enable clinicians to provide targeted intensive care early in pregnancy and thus, reduce the severe morbidity and even mortality associated with the condition. Although low PAPP-A levels did place pregnant women at a higher risk of developing preeclampsia, the predictive value and sensitivity of PAPP-A were relatively low, and hence, it might not be effective as a screening marker. Nevertheless, close monitoring for early detection and intensive care to prevent the development of severe preeclampsia and limiting morbidity may be indicated for women with unexplained low PAPP-A levels. The clinical use of serum PAPP-A level, as a marker of increased risk of preeclampsia, warrants further study.

This study had many strengths and limitations. Its strengths included adequate sample size to satisfy the main objective and the high homogeneity of participants in terms of Thai ethnicities. Its limitations were: (a) the relatively small sample size of pregnancies with low PAPP-A levels, which could limit the generalisability and reliability of conclusions drawn for rare outcomes such as fetal death; (b) its retrospective design that led to a large number of cases with incomplete data and losses to follow-up; and (c) some secondary outcomes that were not well controlled for confounding factors (e.g. women with prior preterm birth were not excluded from the study, so it is likely that the increased prevalence of preterm births in our group may have partly been affected by factors other than low PAPP-A levels). Since women with risk factors for preeclampsia were excluded prior to analysis, we were unable to compare the incidence and severity of preeclampsia between women with low and normal serum PAPP-A levels among pregnancies that would normally be deemed at high risk of preeclampsia. Future studies should look at a full cohort of patients with multivariate analysis to determine whether low PAPP-A levels and the development of preeclampsia later in pregnancy are correlated independent of other factors, and whether women with known risk factors for preeclampsia are at higher risk if they also have low levels of PAPP-A.

In conclusion, pregnancy with PAPP-A levels $<10$ th percentile was significantly associated with an increased risk of preeclampsia that tended to develop early and was possibly associated with other adverse obstetric outcomes. Therefore, pregnant women with low PAPP-A levels in the first trimester should be considered to be at high risk for preeclampsia. However, due to limitations imposed by the retrospective nature of this study, we suggest a future prospective study to confirm our findings and to analyse the diagnostic performance of PAPP-A levels as routine screening for predicting preeclampsia. Its shortcomings notwithstanding, our results do demonstrate the need for further studies aimed at risk identification and prevention of preeclampsia.

\section{ACKNOWLEDGEMENTS}

We wish to thank the National Research University project under Thailand's Office of the Higher Education Commission and Diamond Research Grant of the Faculty of Medicine, Chiang Mai University, Thailand, for financial support.

\section{REFERENCES}

1. Report of the National High Blood Pressure Education Program Working Group on High Blood Pressure in Pregnancy. Am J Obstet Gynecol 2000; 183:S1-S22.

2. Duley L. The global impact of pre-eclampsia and eclampsia. Semin Perinatol 2009; 33:130-7.

3. Sibai BM. Diagnosis and management of gestational hypertension and preeclampsia. Obstet Gynecol 2003; 102:181-92.

4. Sibai B, Dekker G, Kupferminc M. Pre-eclampsia. Lancet 2005; 365:785-99.

5. Poon LC, Kametas NA, Maiz N, Akolekar R, Nicolaides KH. First-trimester prediction of hypertensive disorders in pregnancy. Hypertension 2009; 53:812-8.

6. Fialova L, Malbohan IM. Pregnancy-associated plasma protein A (PAPP-A): theoretical and clinical aspects. Bratisl Lek Listy 2002; 103:194-205.

7. Sun IY, Overgaard MT, Oxvig C, Giudice LC. Pregnancy-associated plasma protein A proteolytic activity is associated with the human placental trophoblast cell membrane. J Clin Endocrinol Metab 2002; 87:5235-40.

8. Lin TM, Halbert SP, Spellacy WN. Measurement of pregnancy-associated plasma proteins during human gestation. J Clin Invest 1974; 54:576-82.

9. McIntyre JA, Hsi B, Faulk WP, Klopper A, Thomson R. Immunological studies of the human placenta: functional and morphological analysis of pregnancyassociated plasma protein A (PAPP-A). Immunology 1981; 44:577-83.

10. Poon LC, Stratieva V, Piras S, Piri S, Nicolaides KH. Hypertensive disorders in pregnancy: combined screening by uterine artery Doppler, blood pressure and serum PAPP-A at 11-13 weeks. Prenat Diagn 2010; 30:216-23.

11. Baumann MU, Bersinger NA, Surbek DV. Serum markers for predicting preeclampsia. Mol Aspects Med 2007; 28:227-44.

12. Yaron Y, Heifetz S, Ochshorn Y, Lehavi O, Orr-Urtreger A. Decreased first trimester PAPP-A is a predictor of adverse pregnancy outcome. Prenat Diagn 2002; 22:778-82.

13. Ong CY, Liao AW, Spencer K, Munim S, Nicolaides KH. First trimester maternal serum free beta human chorionic gonadotrophin and pregnancy associated plasma protein A as predictors of pregnancy complications. BJOG 2000; 107:1265-70.

14. Smith GC, Stenhouse EJ, Crossley JA, et al. Early pregnancy levels of pregnancyassociated plasma protein a and the risk of intrauterine growth restriction, premature birth, preeclampsia, and stillbirth. J Clin Endocrinol Metab 2002; 87:1762-7.

15. Dugoff L, Hobbins JC, Malone FD, et al. First-trimester maternal serum PAPP-A and free-beta subunit human chorionic gonadotropin concentrations and nuchal translucency are associated with obstetric complications: a population-based screening study (the FASTER Trial). Am J Obstet Gynecol 2004; 191:1446-51.

16. Goetzinger KR, Singla A, Gerkowicz S, et al. Predicting the risk of pre-eclampsia between 11 and 13 weeks' gestation by combining maternal characteristics and serum analytes, PAPP-A and free $\beta$-hCG. Prenat Diagn 2010; 30:1138-42.

17. Krantz DA, Hallahan TW, Macri VJ, Macri JN. Maternal weight and ethnic adjustment within a first-trimester Down syndrome and trisomy 18 screening program. Prenat Diagn 2005; 25:635-40.

18. Spencer K, Ong CY, Liao AW, Nicolaides KH. The influence of ethnic origin 
on first trimester biochemical markers of chromosomal abnormalities. Prenat Diagn 2000; 20:491-4

19. Spencer K, Heath V, El-Sheikhah A, Ong CY, Nicolaides KH. Ethnicity and the need for correction of biochemical and ultrasound markers of chromosomal anomalies in the first trimester: a study of Oriental, Asian and Afro-Caribbean populations. Prenat Diagn 2005; 25:365-9.

20. Luewan S, Sirichotiyakul S, Yanase Y, Traisrisilp K, Tongsong T. Median levels of serum biomarkers of fetal Down syndrome detected during the first trimester among pregnant Thai women. Int J Gynaecol Obstet 2012; 117:140-3.

21. American College of Obstetricians and Gynecologists; Task Force on Hypertension in Pregnancy. Hypertension in pregnancy. Report of the American College of Obstetricians and Gynecologists' Task Force on Hypertension in Pregnancy. Obstet Gynecol 2013; 122:1122-31.
22. Spencer K, Bindra R, Nicolaides KH. Maternal weight correction of maternal serum PAPP-A and free beta-hCG MoM when screening for trisomy 21 in the first trimester of pregnancy. Prenat Diagn 2003; 23:851-5.

23. Wolf M, Shah A, Lam C, et al. Circulating levels of the antiangiogenic marker sFLT-1 are increased in first versus second pregnancies. Am J Obstet Gynecol 2005; 193:16-22.

24. Moore Simas TA, Crawford SL, Solitro MJ, et al. Angiogenic factors for the prediction of preeclampsia in high-risk women. Am J Obstet Gynecol 2007; 197:244.e1-8.

25. Lam C, Lim KH, Karumanchi SA. Circulating angiogenic factors in the pathogenesis and prediction of preeclampsia. Hypertension 2005; 46:1077-85.

26. Levine RJ, Maynard SE, Qian C, et al. Circulating angiogenic factors and the risk of preeclampsia. N Engl J Med 2004; 350:672-83. 